\title{
Practice Teaching of Landscape Survey Course Based on eCognition Remote Sensing Image Interpretation* Technology
}

\author{
Xueling Zhang ${ }^{1}$ \\ School of Architecture Tsinghua University
}

\begin{abstract}
With the rapid development of modern $3 \mathrm{~S}$ technology (Remote Sensing, Geography Information Systems, and Global Positioning Systems) and the rise of the digital landscape research globally, it has become the inevitable development trend for the landscape architecture teaching to make full use of Remote Sensing (RS) interpretation technology, improve the landscape survey digital platform, enrich the landscape analysis of objective data, find the inherent law of natural and man-made environment, and stimulate the scientific and technological progress of landscape architecture. To this end, based on the application status of RS image interpretation technology in the field of contemporary landscape architecture, this paper studies the application of eCognition RS image interpretation technology in the practice teaching of landscape survey. Firstly, through comparison of related technologies, the advantages and its teaching application possibility of eCognition image interpretation technology were stated. Secondly, various stages of eCognition RS image interpretation technology in assisting landscape design were analysed, highlighting the teaching application in landscape survey; besides, specific examples were taken to explain and verify how to carry out the practice teaching of landscape survey. Finally, the application characteristics of eCognition RS image interpretation technology and the future development trend of landscape RS teaching were summarized. The application results show that the introduction of eCognition RS image interpretation technology into practice teaching of landscape architecture can effectively improve teaching efficiency and learning effects, and promote the simultaneous development of students' practical ability, analytical ability and judgment ability. Moreover, it has broad application prospects in the teaching parts of landscape survey, assessment, design and performance. The research findings are of great significance to promote the application of RS image interpretation technology in landscape teaching.
\end{abstract}

\section{Keywords}

Landscape Survey $\bullet$ eCognition Image Interpretation $\bullet$ Remote Sensing (RS) $\bullet$ Practice Teaching $\bullet$ Landscape Architecture

\footnotetext{
* I thank ShuHua Li, Ming Zhao, ChongXian Chen and my parents for their indispensable help with this research, I also thank for the RS data support from Beijing Satlmage Information Technology Co., Ltd. The author is grateful to the reviewers and the editors for the time and effort they put into their detailed comments that helped improve this paper.

${ }^{1}$ Correspondence to: Department of Landscape Architecture, School of Architecture, Tsinghua University, Beijing, 100084, China. Email: zhangxueling@ mail.tsinghua.edu.cn
}

Citation: Zhang, X. L, Practice teaching of landscape survey course based on eCognition remote sensing image interpretation technology. Educational Sciences: Theory \& Practice, 18(5), 1411-1423. 
At present, digital technology has been widely applied to various fields of teaching, research and engineering in landscape architecture, and also promoted the continuous development of university education and practice teaching. The inherent teaching methods and means in landscape architecture have been continuously broken through and innovated (Pullar \& Tidey, 2001). Meanwhile, more emphasis has been put on rational thinking and analytical logic in landscape architecture teaching, and then science survey has become an important basis for landscape planning and design (Khwanruthai \& Yuji, 2011). Thus, digital technology plays a more crucial role in landscape survey, analysis, evaluation, planning, design, construction, and even environmental performance (Carrera, 2017). It has become an important way to stimulate the development potential of landscape architecture and promote the landscape architecture education.

In the digital age of the 21st century, digital technology represented by 3S (Remote Sensing, Geography Information Systems, Global Positioning Systems) technology is becoming more important in engineering education (Dong-Gwon Sung, 2001). 3S technology, as a combination of modern space technology, sensor technology, satellite positioning and navigation technology, computer technology, and communication technology, is a multi-disciplinary and highly integrated modern information technology for collecting, processing, managing, analysing, expressing, disseminating and applying environmental information. With the support of $3 \mathrm{~S}$ technology, the specialization and scientization degree of landscape education has been significantly enhanced, the practice teaching has also undergone changes accordingly, and various practical problems can be handled more rationally and systematically. In this way, students can learn and study in a larger spatial extent, their analysis comprehensiveness is enhanced, and the analytical results are more scientific (Liu, Shao, Yao \& You, 2017).

RS technology is a powerful means of acquiring and analysing environmental information. It can provide positioning and quantitative data with large amount of information, strong timeliness, high accuracy, large monitoring range, and comprehensive analysis capabilities (Lv, Ma, Dong, Yao \& Yuan, 2018). Also, RS can quickly and accurately achieve a variety of landscape resource survey and special drawings processing according to different learning and research purposes, and assist in landscape planning and design (Grippa $e t$ $a l .$, 2018), e.g., it can quickly and accurately conduct urban green space resource surveys (such as statistics analysis of green coverage), dynamic monitoring of landscape environment, research of landscape pattern change, and biodiversity survey analysis (Zhang \& Ke, 2016), so as to provide supports for study and research of undergraduates and postgraduates majors in landscape architecture.

However, compared with the wide application of GIS in the teaching of landscape architecture, the RS hasn't been widely applied in teaching process, and related teaching research has started to receive the attention of colleges and universities. The main reasons for this include: the previous RS wasn't open to the society, making it impossible to obtain the RS basic image and carry on related teaching; the spatial information platform construction based on RS technology is relatively lagging behind, and its technical expertise and advantages cannot be exhibited timely; GIS is good at obtaining topographic information, which is suitable for the initial stage of landscape architecture learning, while RS is known for obtaining landform information, more suitable for the in-depth stage of landscape architecture learning; the teachers of landscape architecture speciality in colleges and universities generally have low information technology literacy, since the traditional teaching pays 
more attention to the process of qualitative analysis for students, but focusing less on the teaching of quantitative analysis and rational solution (Amer, Aboelsoud, Omar \& Zoghdan, 2018).

Based on this above, this paper aims to study how to apply RS technology in the practice teaching of landscape architecture. Besides, by taking eCognition RS technology as an example, the technical means and examples were introduced in order to promote the application of RS technology in college landscape teaching. First of all, this paper introduces the relevant key concepts and the digital development process of landscape survey. Then, it expounds the application of eCognition RS technology to various stages of landscape survey, and explain its advantages by comparing it with related software. Finally, eCognition's teaching application examples and practice teaching process was summarized to guide students in landscape environment survey and analysis through computer. The research results are of certain guiding significance for promoting the application of RS technology in landscape survey courses, and also improve the digital landscape teaching.

\section{Overview of key concepts}

\subsection{Practice teaching}

Practice teaching is a teaching activity in which college students learn and train in the real environment or project background, and acquire operational skills, technical experience and innovative ability. It is a learning process that closely combines theory with practice and effectively improves students' ability to solve practical problems. As an indispensable important link in the engineering education system of colleges and universities, practice teaching is conducive to the rapid improvement of college students' engineering literacy and practical ability. Contemporary practice teaching pursues the improvement of comprehensive capabilities and builds a "real-world platform" for innovation capabilities, while imparting knowledge and skills in the field of expertise (Smith \& Vinson, 2014).

Under the guidance of the CDIO model in international engineering education, the knowledge composition and acquisition methods in the relevant knowledge system of landscape architecture have changed drastically. The traditional knowledge export-oriented talent training model has profoundly changed to the innovation ability guided by practice teaching. Digital technology has become the core carrier of today's classrooms and tomorrow's workplace (Wooten, 2018). In view of the comprehensive, practical and logical characteristics in modern landscape architecture education, practice teaching should centre on the cultivation of students' comprehensive ability and creative practice ability, and through digital analysis put emphasis on students' cooperative training of problem discovery, analysis and solving in practice, forming a full-process systematic knowledge structure of "problem discovery and induction $\rightarrow$ scientific assessment and judgment $\rightarrow$ conceptual scheme generation $\rightarrow$ program discussion and deepening $\rightarrow$ outcome expression and verification" (Wu, 2015).

\subsection{Landscape survey}

Landscape survey is an important component of the landscape professional knowledge system. It is the basic condition for the study and practice of landscape architecture, with a strong dual attribute of practice and research itself (Major, Smith and Mackay, 2018). Landscape survey is a general term for the collection, statistics 
and analysis of natural environment or human settlement elements based on the disciplinary vision of landscape architecture (Yang and Li, 2016). Since the publication of Mc Harg's "Design with Nature", landscape survey has gradually evolved from traditional intuitive judgment to rational analysis, and by the map overlay method, it has developed rapidly toward digital analysis supported by computer technology (Ozdemir, Mert and Senturk, 2012). Fig.1 shows that compared with traditional manual identification of drawings, on-site survey and recording, RS can quickly monitor changes in urban green space, and obtain quantitative data on green area and tree species. It is a contemporary advanced landscape survey method.
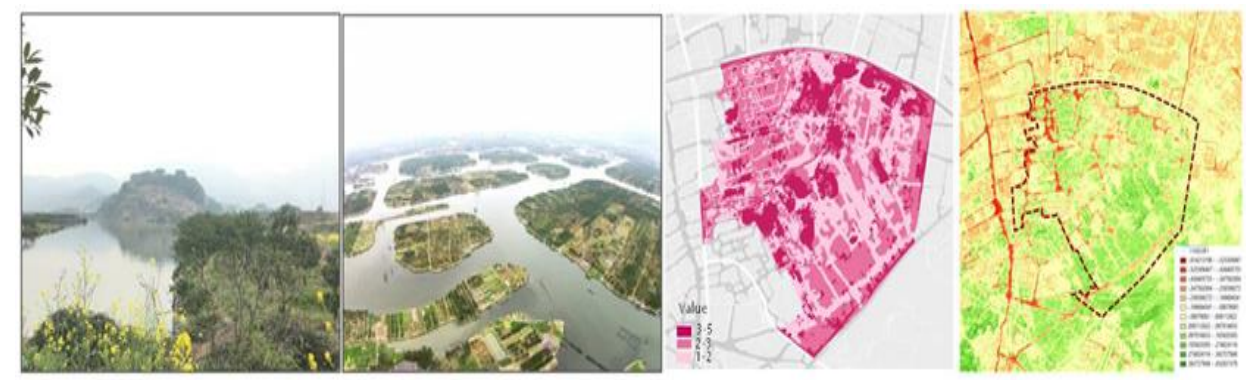

Figure 1. Four methods of landscape survey in the same environment (visit, aerial photography, GIS, RS survey from left to right)

\section{3 eCognition remote sensing image interpretation technology}

2.3.1 eCognition. eCognition is an intelligent image analysis software developed by Definiens Imaging of Germany. It is also the first RS information extraction software based on target information in all commercial remote sensing software. It breaks through the limitations of traditional image classification methods and proposes a revolutionary classification technique-object-oriented classification. The eCognition classification is aimed at objects rather than pixels in the traditional sense, making full use of object information (hue, shape, texture, level), inter-class information (related features of neighbouring objects, sub-objects, parent objects), thus greatly improving the automatic recognition accuracy of spatial resolution data. It effectively satisfies the needs of scientific research and engineering applications in natural resources and environmental surveys, agriculture, forestry, land use, coastal zone and marine mapping, and also has broad application prospects in landscape architecture (Nagabhatla and Kuhle, 2016).

2.3.2 Features of eCognition remote sensing image interpretation technology. Based on the simulation of human brain cognitive processes, eCognition uses object-oriented image interpretation technology to identify and recognize targets from different scales and surrounding environments. It is the perfect combination of computer high-speed processing and human cognitive principles, also in consideration of speed and accuracy of information extraction processing (Chmielewski, 2014). In the past 10 years of development, eCognition RS image interpretation technology has always provided technical solutions for the industry's leading data providers, product valuers, remote sensing and related fields. The technical features of eCognition in landscape survey are as follows: 
(1) Advanced classification technology

Compared with traditional pixel-based analysis techniques, eCognition RS image interpretation technology is closer to human cognitive processes. Unlike other traditional image analysis extraction methods and software, the basic processing unit extracted by eCognition is the image object and its interrelated or image segmented part, rather than a single pixel, and its classification is based on image objects.

(2) Rich image features and algorithms

eCognition provides more than 200 classification features and over 1,000 analytical algorithms, including shape, hue, texture, and environmental information, as well as different object layer related features and algorithms, so that the semantic difference between categories is more obvious, and the relevant classification accuracy is very high.

(3) Multi-scale segmentation technology

eCognition can provide multi-scale RS image segmentation methods, and then combines feature elements with expert knowledge base for information interpretation and extraction. These image treating procedures are mutually influential cyclic processes and are ones of the most advanced contents in RS image information extraction technology.

(4) Comprehensive response to landscape survey tasks

Currently, eCognition can satisfy most landscape survey tasks. It can effectively solve the problem of multidata fusion by assigning the same value to image information from different sources. At the same time, based on the characteristics of landscape surveys, eCognition allows users to combine classification factors (such as spectra, textures, and shapes) of different object attributes, and use context information and semantic information to classify complex landscape images (such as buildings that are obscured by trees).

\subsection{Review of RS technology development in landscape survey}

Traditional RS technology is rarely used in landscape surveys, mainly because its information extraction methods are based on the statistical characteristics of pixels, making it impossible to effectively use the landscape feature information such as the shape and geometric structure of the surface features, and the classification accuracy and analysis efficiency aren't high (Bidgoli, 2018). With the increasing accuracy of RS satellite imagery, high-resolution RS images with rich geometric features and texture information have expanded the research horizon of landscape survey, and object-oriented information extraction technology makes it possible. Lobo (1996) used the goal-based information extraction concept to carry out theoretical classification research on RS images of landscape environment, achieving good results, and also obtained more complete maps; Hofmann (2001) identified the residential areas in the IKONOS image with high precision by the spectrum, texture, shape and background information of image objects; Hellwich (2000) applied the eCognition RS image interpretation technology to effectively extract the natural environment landscape resource map and classify it systematically; Mauro (2001) adopted Per-field method to integrate high-resolution RS imagery and topographic data for landscape resource classification research; Qin (2006) used the object- 
oriented classification method to carry out landscape survey of forest environment, with 43 classifications, and achieved satisfactory results.

\section{eCognition-aided landscape survey}

\subsection{Comparative analysis of commonly used RS software for landscape survey}

Table 1 compares the commonly used RS image analysis software in landscape survey. The eCognition software has broad application prospects in landscape teaching because of its rich plug-ins, simple operation, strong interaction, fast parsing speed and support for custom algorithms.

Table 1

Comparison of Five Commonly Used RS Image Analysis Software

\begin{tabular}{llllllc}
\hline Software & $\begin{array}{c}\text { Analysis } \\
\text { ability }\end{array}$ & $\begin{array}{l}\text { Analysis } \\
\text { accuracy }\end{array}$ & $\begin{array}{c}\text { Learning } \\
\text { difficulty }\end{array}$ & $\begin{array}{c}\text { Interface } \\
\text { friendliness }\end{array}$ & $\begin{array}{c}\text { Algorithms } \\
\text { quantity }\end{array}$ & $\begin{array}{c}\text { Design } \\
\text { oriented }\end{array}$ \\
\hline ENVI & Very powerful & Higher & Ordinary & Ordinary & Many & Yes \\
Geomatica & Ordinary & Ordinary & Hard & Unfriendly & Many & Yes \\
Qmosaic & Ordinary & Ordinary & Ordinary & Ordinary & Many & No \\
eCognition & Very powerful & Higher & Easy & Friendly & Great many & Yes \\
ERDAS & Powerful & High & Hard & Friendly & Great many & No \\
\hline
\end{tabular}

\subsection{Application advantages of eCognition in landscape survey practice teaching}

The landscape survey is a process of scientific cognition for the basic elements of the landscape environment. Through the investigation and cognition of the site conditions, it makes reasonable judgment and utilization of the ecological environment, spatial pattern and the background of human settlements on the basis of maximizing respect for nature (Li, 2018). Landscape survey should make full use of 3S technology including eCognition on the basis of on-site survey, photographing and recording so as to realize data collection and graphical representation of different types of environmental elements in the environment, and then provide detailed and reliable basic data and accurate basic drawings for the follow-up and new construction actions (Frauenfelde, Lato \& Biskupic, 2015).

Table 2

Main Contents of Landscape Survey Using Remote Sensing

\begin{tabular}{|c|c|c|}
\hline \multirow{4}{*}{ Natural factors } & Vegetation & $\begin{array}{l}\text { Vegetation community and morphology, tree, shrub, ground } \\
\text { cover, aquatic plant, et al. }\end{array}$ \\
\hline & Terrain & $\begin{array}{l}\text { Distribution of land and surface water, altitude, slope, slope } \\
\text { direction, catchment area, et al. }\end{array}$ \\
\hline & Hydrology & Water form, depth, quality, distribution of aquatic plants, et al. \\
\hline & Soil & Surface soil and rock, soil type, et al. \\
\hline \multirow[b]{2}{*}{ Artificial factors } & Structure & Distribution, spatial form, height, quality of construction, et al. \\
\hline & Historical remains & $\begin{array}{l}\text { Identification and discovery of historical remains, } \\
\text { morphological character, material and color, et al. }\end{array}$ \\
\hline \multirow{2}{*}{$\begin{array}{l}\text { Environment } \\
\text { condition }\end{array}$} & Road & $\begin{array}{l}\text { Distribution, road width, construction situation, pavement } \\
\text { materials, et al. }\end{array}$ \\
\hline & $\begin{array}{l}\text { Construction } \\
\text { condition }\end{array}$ & Land type, space distribution, social activities, et al. \\
\hline
\end{tabular}

In the practice teaching of landscape survey, eCognition has become the preferred technology for RS image interpretation. In addition to the accurate identification and graphic processing of natural elements, artificial 
elements and environmental conditions in the landscape environment (Table 2), eCognition RS image interpretation technology can comprehensively analyse and deal with the spatial properties of natural elements in the landscape environment, and judge the morphological relationship and composition law of the landscape space interface with its rich algorithm support, to realize the comprehensive processing of large-scale topography (Wang Lu \& Yang, 2018). Therefore, it plays a leading role in the existing RS interpretation technology with excellent teaching application advantages.

\section{Practice teaching example of eCognition-aided landscape survey}

\section{Overview of practice teaching}

Teaching hardware and software environment. Computer configuration: CPU, Intel Core i7, quad-core CPU with basic frequency of $2.6 \mathrm{~Hz}$; video card: no less than single graphics card (discrete graphics or integrated graphics); hard disk: no less than 500G; memory: no less than 8GB; operation System: 64-bit Windows 8 operating system; eCognition RS image analysis software, ENVI RS image processing software, or ArcGIS if needed.

eCognition based on the Windows operating system has strong expansibility and compatibility in the RS image analysis software for landscape design, e.g., eCognition can integrate GIS data as the basic image or thematic layer of classification; it can also cooperate with RS image processing platforms such as ENVI to complete complex image analysis tasks.

eCognition can analyse the earth observation data and GIS data at different resolutions, such as QuickBird, Landsat, SPOT, IKONOS, SAR, LIDAR, aerial photos, etc. Different types of image data and vector data can participate in object segmentation and classification simultaneously. The earth observation data and GIS data are widely available. Basic data such as terrain, laser point cloud, elevation data, and GIS data can be obtained through Google Earth, airborne LiDAR system, CAD, ArcGIS, etc. RS images of different precisions can be obtained through the website of remote sensing information. In China, the RS images for college students can be applied for on the official website of the No. 3 satellite. After approval, they can obtain free remote sensing image data for learning.

\section{Teaching objectives}

Landscape survey is an important part of the landscape knowledge system. It is an important way for students to train their exploration ability and innovation capacity. eCognition remote sensing interpretation technology can quickly upgrade the traditional research mode to digital and information mode, so as to effectively form the practice teaching atmosphere of "focusing on remote sensing image research and analysis, students' autonomous learning, and learning community of teachers-students" during the process of practice teaching.

On this basis, scientific learning plans and subject content are made to further improve the proportion of practical learning and teaching, so that students can obtain effective knowledge in personal operation, and grasp the progress of remote sensing technology, while mastering the eCognition RS analysis technology. This also 
reserves a technical interface for the comprehensive application of $3 \mathrm{~S}$ in landscape architecture planning and design, which can promote the establishment and sustainable development of students' digital technology knowledge system.

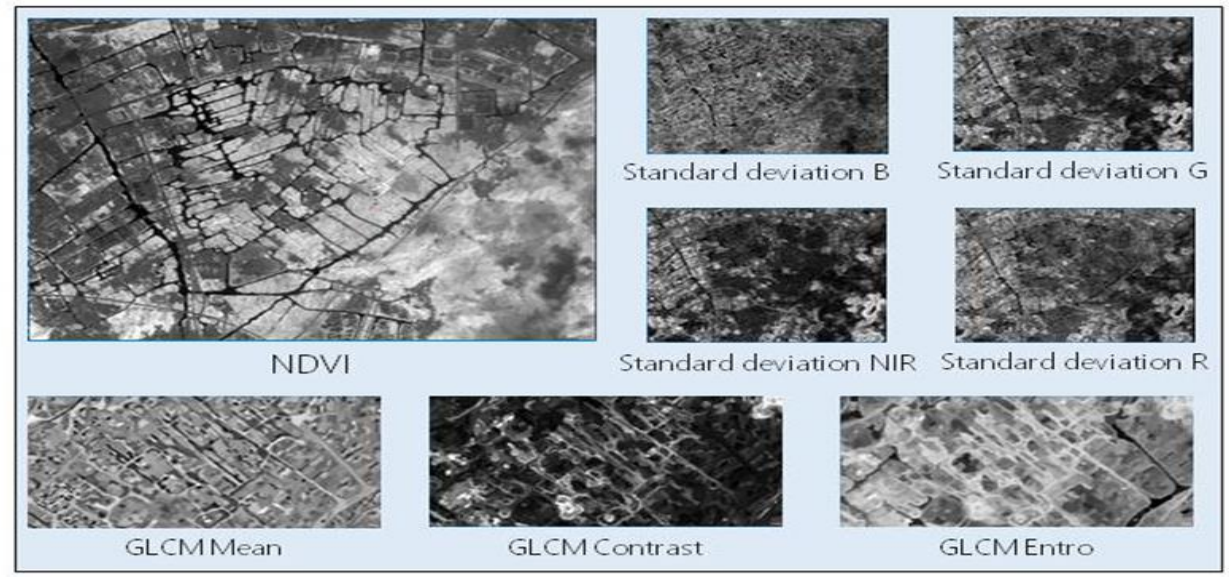

Figure 2. Basic processing of eCognition-aided landscape survey images
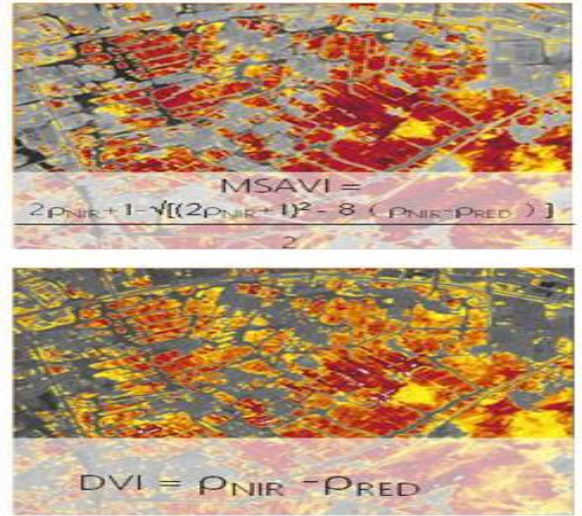
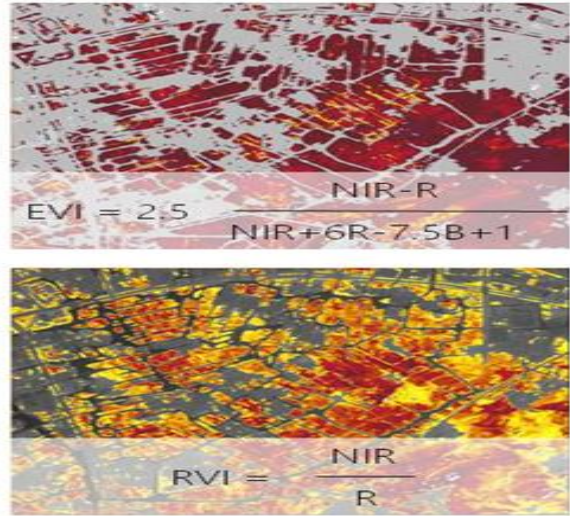

Figure 3. Algorithm analysis of eCognition-aided landscape survey images

Teaching procedures and examples. As a highly technical practice course, practice teaching of eCognitionaided landscape survey should avoid the separation of theoretical teaching from practical operation, and lack of systemization in curriculum content. It should fully realize the orderly connection and progressive deepening of knowledge points in practical teaching. On the basis of overall cognition, practice teaching should focus on the eCognition basic function module teaching closely related to landscape survey, and design RS image processing experiments in combination with actual projects. The relevant teaching examples are shown in Fig.25 (China's Wenzhou Sanyang Wetland, with 240 hectares landscape survey scale).

First of all, through simple image pre-processing, students can master the basic concepts of RS images, and start operation study and practice of image conventional processing. On this basis, combined with examples 
and key knowledge points, students' ability to learn, explore and operate independently is further cultivated. The experimental contents include:

(1) Basic processing of RS images (Fig.2), including image cropping and data format conversion.

(2) RS image enhancement algorithms (Fig.3), including spatial domain enhancement processing and radiation domain enhancement processing.

(3) Geometric correction of RS image; ground control point (on-site determination) and geometric correction mathematical model are used to correct the error caused by non-system factors and solve the geometric distortion problem of the image.

(4) RS image fusion; based on precise registration, the appropriate fusion method is selected to superimpose the two images and then generate a new fused image.

(5) Classification of RS images (Fig.4); appropriate classification methods are selected to segment the RS images for practice; each group often conducts comparative teaching of classification methods to study the matching accuracy of the segmentation techniques and research objectives.

(6) In the 32-hour course teaching, two examples of landscape survey (10-20 hectares, 1-1.5 square kilometres, respectively) were arranged. According to the order of vegetation, water, bare soil (rock), roads, buildings (trees are blocked, so it has relatively more research values), RS image analysis and image generation practice teaching were carried out (Fig.5).

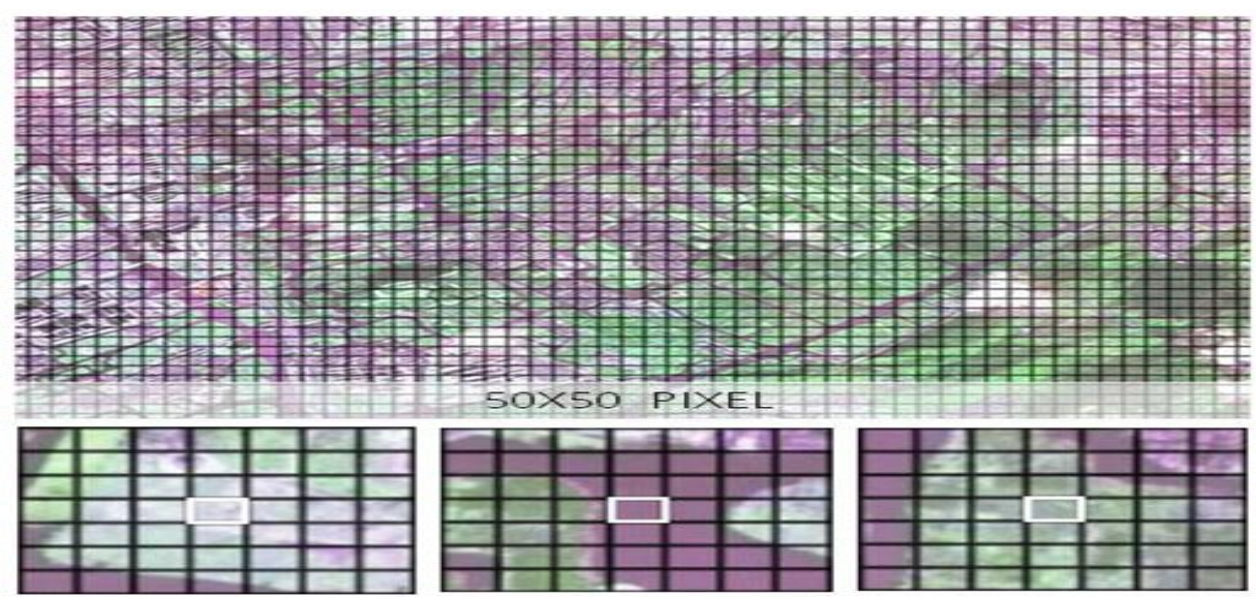

Figure 4. Division and classification of eCognition-aided landscape survey images

In addition, teachers can generalize specific problems (such as hot issues - target detection problems, material judgment problems, geometric division scale optimal solutions, etc.) in terms of different topical knowledge and form a special discussion; or according to the students' research direction, research progress and eCognition application level, practical problems were set separately, and then the students independently explore specific algorithms in order to promote the simultaneous development of their operational capabilities and research capabilities. 


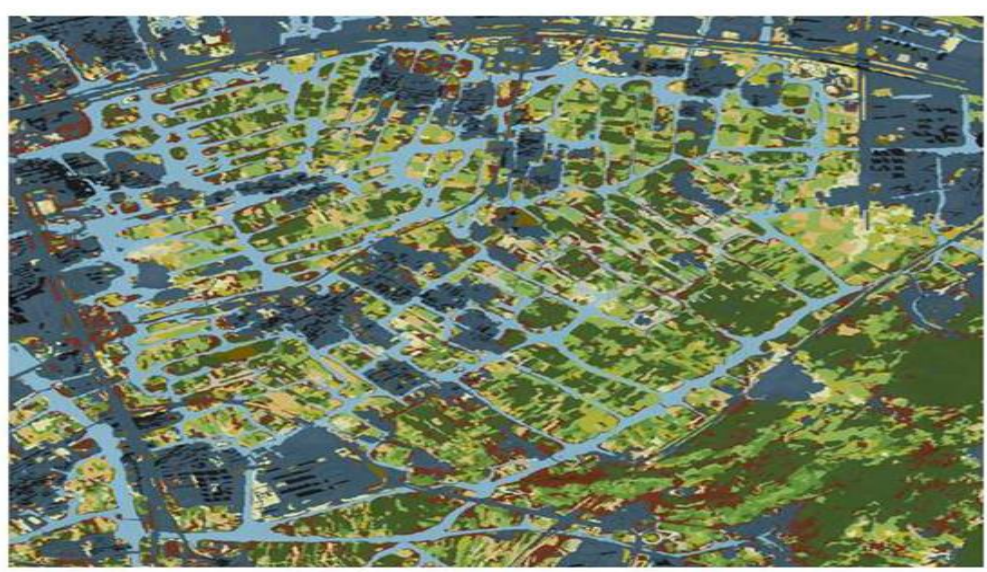

Figure 5. Landscape survey map based on eCognition RS image interpretation technology

\section{Teaching prospects}

Practice teaching of landscape survey based on eCognition RS image interpretation technology is a new type of landscape teaching course with the internal requirements of landscape architecture, computer and related RS technology. It uses contemporary RS technology to support the survey stage in landscape teaching and practice, and logically generate methods and means to solve problems, which helps to integrate and deal with common problems in landscape surveys and has positive learning value (Hulet A., 2014). Colleges of Landscape architecture in China, the United States and some European countries have successively set up similar courses, which in fact shows that eCognition provides a good technical platform for landscape architecture professionals to effectively carry out RS teaching.

The exploration of practice teaching represented by landscape survey provides a learning approach characterized by objective quantitative analysis and multi-dimensional visual presentation for landscape architecture professional education, and also technical solutions for relevant landscape theory knowledge analysis, scientific research counselling and planning design. It is of great reference significance.

The effective combination of technology and practice can profoundly change the phenomena in the traditional teaching of landscape architecture, such as relying on experience teaching, lack of rational support, subjective and random teaching methods, and can also improve the efficiency and scientificity of students' learning, research and practical exploration. It is conducive to the effective integration of the teachers' teaching in landscape architecture and students' independent research, creating favourable conditions for the reform of teaching methods and the cultivation of students' innovative ability.

\section{Conclusions}

Based on the $3 \mathrm{~S}$ technical education situation evaluation and the practical teaching mode analysis of landscape architecture speciality, this paper conducts a phased theoretical analysis and practical exploration on 
the application of eCognition RS image analysis technology in landscape survey practice teaching. The paper makes the following conclusions:

(1). With the eCognition RS technology applied to the landscape survey practice classroom, RS technology can be quickly and effectively connected with the landscape architecture knowledge system, expand the knowledge domain of landscape architecture professional education, make landscape survey more scientific, and rapidly improve people's vision to Satellite vision. This is one evolution of landscape architecture.

(2). Through the practical learning of RS technology represented by eCognition, the students majored in landscape architecture can master the environmental data collection techniques and methods of landscape surveys at different scales. The introduction of a series of new RS and mapping technologies and methods has promoted the establishment of scientific concepts in young people's minds, thus stimulating the strong interest of college students in in-depth study. This is another technological revolution in landscape architecture discipline.

\section{References}

Amer, M. M., Aboelsoud, H. M., Omar, E. H., \& Zoghdan, M. G. (2018). Assessing the impact of shallow groundwater on soil salinity and biomass yield of plants grown in North Nile delta using remote sensing and GIS. Egyptian Journal of Soil Science. 58(1), 57-71. http://dx.doi. org/10.21608/ejss.2017.1909.1135

Bidgoli, R. D., Koohbanani, H., \& Yazdani, M. (2018). Investigation on ecosystem degradation induced by LU/LC changes using landscape pattern indices analysis. Arabian Journal of Geosciences, 11(16), 443. http://dx.doi. org/10.1007/s12517-018-3798-6

Carrera, C. C., \& Asensio, L. A. B. (2017). Augmented reality as a digital teaching environment to develop spatial thinking. Cartography and Geographic Information Science, 44(3), 259-207. http://dx.doi. org/10.1080/15230406.2016.1145556

Chmielewski, S. (2014). Land cover and landscape diversity analysis in the West Polesie Biosphere Reserve. International Agrophysics, 28(2), 153-162. http://dx.doi. org/10.2478/ intag-2014-0003

Frauenfelder, R., Lato, M. J., \& Biskupic, M. (2015). Using ecognition to automatically detect and map avalanche deposits from the spring 2009 avalanche cycle in the tatra mts., Slovakia. 36th International Symposium on Remote Sensing of Environment, 47(w3), 791-795. http://dx.doi. org/10.5194/isprsarchivesXL-7-W3-791-2015

Grippa, T., Georganos, S., Zarougui, S., Bognounou, P., Diboulo, E., Forget, Y., \& Wolff, E. (2018). Mapping urban land use at street block level using openstreetmap, remote sensing data, and spatial metrics. ISPRS International Journal of Geo-Information, 7(7), 246.http://dx.doi. org/10.3390/ijgi7070246

Hellwich, O., \&vWiedemann, C. (2000). Object Extraction from High-Resolution Multisensor Image Data. 3rd International Conference on Fusion of Earth Data Sophia Antipolis. France.

Hofamnn, P. (2001). Detection informal settlements from IKONOS image data using methods of objectoriented image analysis: An example from Cape Town (South Africa). Remote Sensing of Urban Areas. F Enerkundung in Urbanen Raumen. 41-42. 
Hulet, A., \& Roundy, B. A. (2014). Cover estimations using object-based image analysis rule sets developed across multiple scales in Pinyon-Juniper woodlands. Rangeland Ecology \& Management, 67(3), 318-327. http://dx.doi. org/10.2111/REM-D-12-00154.1

Khwanruthai, B., \& Yuji, M. (2011). Site suitability evaluation for ecotourism Using GIS \& AHP: A case study of Surat Thani Province, Thailand. Procedia Social and Behavioral Sciences. 2011. 21. 269-278. http://dx.doi. org/10.1016/j.sbspro.2011.07.024

Li, Z., Cheng, Y. N., \& Xiao, R. (2018). Electroencephalogram Experiment Based Analysis of Aesthetic Fatigue on Chinese Traditional Garden. NeuroQuantology, 16(5), 356-362. DOI: 10.14704/nq.2018.16.5.1296

Liu, M. H., Shao, Y., Yao, J., \& You, Y. C. (2017). Research on Teaching System Construction of Applied Surveying Engineering Specialty with "3S" as the Core. Proceedings of the 2017 International Conference On Education Science And Economic Management (Icesem 2017), 106, 407-410.

Lobo, A., Chic, O., \& Casterad, A. (1996). Classification of Mediterranean Crops with Multi-sensor Data: Perpixel Versus Per-object Statistics and Image Segmentation. International Journal of Remote Sensing, (17), 2358-2400.

Lv, J., Ma, T., Dong, Z., Yao, Y., \& Yuan, Z. (2018). Temporal and Spatial Analyses of the Landscape Pattern of Wuhan City Based on Remote Sensing Images. ISPRS International Journal of Geo-Information, 7(9), 340. http://dx.doi. org/10.3390/ijgi7090340

Major, J., Smith, C., \& Mackay, R. (2018). Reconstructing landscape: Archaeological investigations of the royal exhibition buildings western Forecourt, Melbourne. International Journal of Historical Archaeology, 22(1), 43-66. http://dx.doi. org/10.1007/s10761-017-0414-5

Mauro, C., \& Eufemia, T. (2001). Accuracy assessment of per-field classification integrating very fine spatial resolution satellite imagery with topographic data. Journal of Geospatial Engineering, 3(2), 127-134.

Nagabhatla, N., \& Kuhle, P. (2016). Tropical Agrarian landscape classification using high-resolution GeoEYE data and segmentation based approach. European Journal of Remote Sensing, 49. 623-642. http://dx.doi. org/10.5721/EuJRS20164933

Ozdemir, I., Mert, A., \& Senturk, O. (2012). Predicting landscape structural metrics using aster satellite data. Journal of environmental engineering and landscape management, 20(2), 168-176. http://dx.doi. org/10.3846/16486897.2012.688371

Pullar, D. V., \& Tidey, M. E. (2001). Coupling 3D visualisation to quanlitative assessment of built environment designs. Landscape and Urban Plannning. 55(1), 29-40. http://dx.doi. org/10.1016/S0169-2046(00)001481

Qin, Y., \& Peng, G. (2006). Object-based detailed vegetation classification with airborne high spatial resolution remote sensing imagery. Photogrammetric Engineering and Remote Sensing, 72(7), 799-811. http://dx.doi. org/10.14358/PERS.72.7.799

Smith, M. K., Vinson, E. L. (2014). A Campus-Wide Study of STEM Courses: New Perspectives on Teaching Practices and Perceptions. Cbe-Life Sciences Education, 13(4), 624-635. http://dx.doi. org/10.1187/cbe.1406-0108

Sung, D. G., Lim, S. H., Woong, J., \& Cho, G. S. (2001). scenic evaluation of landscape for urban design purposes Using GIS and ANN. Landscape and Urban Planning, 56, 75-85. http://dx.doi. org/10.1016/S0169-2046(01)00174-8 
Wang, Z. H., Lu, C., \&Yang, X. M. (2018). Exponentially sampling scale parameters for the efficient segmentation of remote-sensing images. International Journal of Remote Sensing, 39(6), 1628-1654. http://dx.doi. org/10.1080/01431161.2017.1410297

Wooten, M. M. (2018). A Cartographic Approach Toward the Study of Academics' of Science Teaching and Learning Research Practices and Values. Canadian Journal of Science Mathematics And Technology Education. 18(3), 210-221. http://dx.doi. org/10.1007 / s42330-018-0029-9

Wu, S. S. (2015). Design/build teaching practice in architectural design basic course based on CDIO mode. 2015 3rd International Conference on Education Reform and Management Innovation (ERMI 2015), 79, 50-54.

Yang, B., \& Li, S. J. (2016). Design with nature: Ian McHarg's ecological wisdom as actionable and practical knowledge. Landscape and Urban Planning. 155. 21-32. http://dx.doi. org/10.1016/jlandurbplan. 2016.04.010

Zhang, Z. B., \& Ke, C. Q. (2016). Monitoring and analysis of changes in a wetland landscape in Xingzi county. Earth science informatics, 2016. 9(1), 35-45. http://dx.doi. org/10.1007/s12145-015-0232-4 